\title{
Coiled-coil inspired functional inclusion bodies
}

\author{
Marcos Gil-Garcia, Susanna Navarro and Salvador Ventura* (i)
}

\begin{abstract}
Background: Recombinant protein expression in bacteria often leads to the formation of intracellular insoluble protein deposits, a major bottleneck for the production of soluble and active products. However, in recent years, these bacterial protein aggregates, commonly known as inclusion bodies (IBs), have been shown to be a source of stable and active protein for biotechnological and biomedical applications. The formation of these functional IBs is usually facilitated by the fusion of aggregation-prone peptides or proteins to the protein of interest, leading to the formation of amyloid-like nanostructures, where the functional protein is embedded.

Results: In order to offer an alternative to the classical amyloid-like IBs, here we develop functional IBs exploiting the coiled-coil fold. An in silico analysis of coiled-coil and aggregation propensities, net charge, and hydropathicity of different potential tags identified the natural homo-dimeric and anti-parallel coiled-coil ZapB bacterial protein as an optimal candidate to form assemblies in which the native state of the fused protein is preserved. The protein itself forms supramolecular fibrillar networks exhibiting only a-helix secondary structure. This non-amyloid self-assembly propensity allows generating innocuous IBs in which the recombinant protein of interest remains folded and functional, as demonstrated using two different fluorescent proteins.

Conclusions: Here, we present a proof of concept for the use of a natural coiled-coil domain as a versatile tool for the production of functional IBs in bacteria. This a-helix-based strategy excludes any potential toxicity drawback that might arise from the amyloid nature of $\beta$-sheet-based IBs and renders highly active and homogeneous submicrometric particles.
\end{abstract}

Keywords: Coiled-coil protein, Fusion tag, Functional inclusion bodies, Fluorescent proteins, Protein engineering

\section{Background}

Biotechnological and pharmaceutical industries exploit microorganisms as cell factories in order to produce their biological products, including therapeutic proteins, such as hormones, enzymes for replacement therapies, or antibodies $[1,2]$. However, the production of these molecules in their soluble and functional states faces significant barriers $[3,4]$. Proteins have been shaped by natural selection to remain soluble and functional under physiological

*Correspondence: salvador.ventura@uab.cat Institut de Biotecnologia i de Biomedicina and Departament de Bioquímica i Biologia Molecular, Universitat Autònoma de Barcelona, 08193 Bellaterra, Barcelona, Spain conditions, according to the "living on the edge" hypothesis [5]. The heterologous expression of these molecules in bacteria leads to intracellular concentrations that are several times above their natural solubility limits. As a result, these proteins might establish non-native intermolecular interactions, which would facilitate their aggregation into inclusion bodies (IBs) in the bacterial cytosol [6].

Traditionally IBs were thought to be formed by misfolded conformations and thus devoid of any functionality. However, data is accumulating to indicate that, at least for specific proteins and production conditions, IBs might exhibit significant activity [7, 8]. IBs are easy to purify and can be stored for long periods, thanks 
to their inherent stability [9]. They have a nanometric size $(50-1000 \mathrm{~nm})$ [9-12], and $~ 90 \%$ of them are composed of the target protein [13-15]. These properties, combined, make them active nanoparticles, which are finding increasing applications in biotechnology and biomedicine. In this way, the ability to immobilize enzymes in IBs has been exploited to build up reusable catalysts [16, 17], and IBs have been used as nanocarriers or/and nanopills to deliver antitumoral polypeptides in the body $[18,19]$.

We have shown that, generically, a significant proportion of the protein contacts that sustain IBs have an amyloid-like nature [20-22]. When embedded in IBs, proteins exhibit a significant increase in $\beta$-sheet content, relative to their soluble counterparts, and, often, become able to bind typical amyloid dyes. For specific proteins or protein fusions, this amyloid scaffold coexists with functional conformations [23, 24]. However, because the process of protein aggregation into non-native intermolecular $\beta$-sheet structures necessarily involves the population of misfolded species, a fraction of the recombinant protein is necessarily inactivated to build up the amyloid structure that sustains the IB [22].

IBs have been assimilated to natural functional amyloids [25], which are non-toxic for their host cells or organisms [26-28]. However, different studies indicate that this is not because functional amyloids are intrinsically non-cytotoxic [29], but instead because, in these specific cases, nature has evolved dedicated mechanisms to prevent amyloid-associated toxicity [27, 30, 31]. The artificial formation of IBs lack these natural control mechanisms and, although bacterial aggregates have been assumed to be innocuous, it cannot be entirely discarded that toxic $\beta$-sheet conformations can be incorporated or released from these amyloid-like inclusions.

In order to overcome the two above-described limitations, we introduce here an IBs production strategy that exploits a natural coiled-coil protein to promote nonamyloid supramolecular interactions. In the last years, the use and design of coiled-coil domains as building blocks in protein assemblies have attracted significant attention [32,33]. The self-organization capacity of these structures has been exploited to create different nanostructures, such as nanofibers [34] and nanocages [35, 36]. Furthermore, two different coiled-coil domains have been previously used to generate active IBs: the tetramerization domain of the tetrabrachion protein (TDoT) from Staphylothermus marinus [16, 37-40] and the 3HAMP coiled-coil, which was derived from the oxygen sensor protein Aer2 from Pseudomonas aeruginosa [37, 41]. In this work, we apply this strategy to build up functional IBs using ZapB, a non-essential Escherichia coli (E. coli) protein consisting of two anti-parallel $\alpha$-helices, involved in Z-ring formation during the bacterial cell division process $[42,43]$.

We first show that the ZapB self-assembles to form $\alpha$-helix-based fibrillar networks, and afterward, we demonstrate how this property allows its use as a tag to form non-amyloid and non-toxic IBs which preserve the activity of the attached polypeptides.

\section{Results and discussion}

Selection of a polar and non-aggregating coiled-coil protein for the production of functional IBs

A wide range of fusion tags has been used to induce IBs formation. They comprise small artificial peptides [44], and aggregation-prone natural proteins or domains [22, $37,45]$, which are fused to functional globular proteins. A characteristic property of most of these tags is that they promote the formation of aggregates sustained by collective intermolecular $\beta$-sheet interactions. Alternatively, two different coiled-coil domains have been used for the production of fluorescent and/or catalytically IBs [37]. Nevertheless, the biophysical properties of these active aggregates were not assessed, and thus it is not known if the coiled-coil encoding sequences keep their native helical structure in the IBs or they had just transitioned to a conventional amyloid-like assembly. Indeed, the formation of $\beta$-sheet-rich amyloid fibrils by aggregation-prone coiled-coil sequences is behind the onset of several neurodegenerative disorders [46]. A similar transition in coiled-coil-tagged proteins during IBs formation might turn these aggregates potentially toxic.

We selected the E. coli protein ZapB as a scaffold to obtain functional IBs. ZapB is an 81 residues-long protein whose 3D-structure (PDB: 2JEE) consists of two $\alpha$-helical polypeptide chains arranged in anti-parallel orientation to form a dimeric coiled-coil of $116 \AA$ (PDB: 2JEE) [42]. In the crystal structure, individual coiled-coils interact close to their termini, which already suggested that, under appropriate conditions, these helical modules might self-assemble into supramolecular structures [42].

The propensity to form a stable coiled-coil assembly in solution is encoded in the protein sequence. The higher the coiled-coil propensity, the lowest the probability to transition into an aggregated $\beta$-sheet structure since stable $\alpha$-helices protect against aggregation $[47,48]$. We calculated the coiled-coil propensity of ZapB and compared it with that of the two coiled-coil domains used as IBs formation tags in previous studies (3HAMP and TDoT) using four different algorithms: COILS [49], PCoils [50], MARCOIL [51] and DeepCoil [52]. Additional file 1: Figures S1-S3 show the coiled-coil probability profiles for ZapB, 3HAMP and TDoT. The four algorithms coincide to predict a very high coiled-coil propensity along the complete ZapB sequence. In the case of 3HAMP, the 
programs identify a region of high propensity close to the $\mathrm{N}$-terminus and two additional stretches with low to moderate propensity. This is consistent with the homodimeric 3HAMP structure, in which parallel monomers exhibit three successive domains (HAMP1, 2, and 3), each about 50 residues long and bridged by flexible linkers. For TDoT, only DeepCoil is able to identify a significant coiled-coil propensity in the central part of the sequence. This makes sense, since TDoT is a parallel and right-handed coiled-coil tetramer, which is based on the 11-residue repeat, and COILS, PCoils and MARCOIL were trained to identify canonical heptad repeats, where DeepCoil was aimed to identify both kinds of periodicities. Therefore, we used this last algorithm to compare the average coiled-coil probabilities of ZapB, TDoT and 3HAMP primary sequences. As it can be seen in Fig. 1 ZapB seems to be a better coiled-coil former than the proteins it has been compared to.

Not only the coiled-coil propensity accounts for the ability to maintain the native state in the multimeric state, but also the protein's intrinsic aggregation propensity, which facilitates the conformational shift to aggregated $\beta$-sheet states. We analyzed this property for ZapB, TDoT, 3HAMP, and other three non-coiledcoil sequences used previously as IB-tags, namely the amyloid $\beta$-peptide $(\mathrm{A} \beta 42)$ [53, 54], the viral capsid peptide VP1 $[45,55]$, and the signal sequence of $E$. coli TorA (ssTorA) [56, 57]. In order to do that, we used two of the most popular sequence-based aggregation prediction servers, Aggrescan [58] and TANGO [59]. As it can be seen in Fig. 2a, b, ZapB was predicted as the least aggregation-prone sequence in this polypeptide set. Aggrescan (Fig. 2a), predicts ZapB to be the most soluble sequence with a significant difference, relative to the other proteins or domains. In the case of TANGO (Fig. 2b), ZapB remains as the less aggregation-prone sequence, in this case, together with ssTorA.

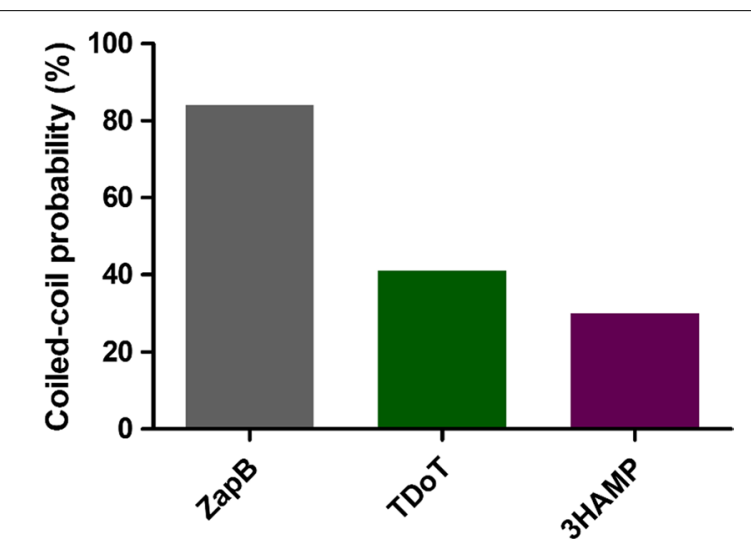

Fig. 1 Coiled-coil probability for ZapB, TDoT, and 3HAMP. The coiled-coil propensity is represented according to DeepCoil predictor
Polarity and hydrophobicity are critical negative and positive contributors to protein sequence aggregation propensity, respectively. Their role is crucial at the nucleation step of the aggregation reaction $[60,61]$. These biophysical properties were analyzed by calculating the Grand Average of Hydropathicity (GRAVY score) provided by the ProtParam server, according to the Kyte-Doolittle scale [62]. Positive GRAVY scores indicate higher hydrophobicity, whereas negative values correspond to polar sequences. As it is shown in Fig. 2c, ZapB has the more negative GRAVY score $(-0.980)$, being this value three times higher than the secondly ranked sequence (VP1, GRAVY score $=-0.307$ ), thus indicating that ZapB is a highly polar protein, relative to compared sequences.

We also checked the secondary structure propensity of the six tags. Cryptic regions of significant $\beta$-sheet propensity might exist even in sequences that usually fold into $\alpha$-helices [63]. These stretches might favor aggregation into amyloid-like structures upon coiled-coil unfolding or once the polypeptide chain emerges from the ribosome [64]. To this aim, we used the PSIPRED [65] and GOR [66] servers. ZapB is predicted to be completely $\alpha$-helix, with an extremely high propensity for this secondary structure; meanwhile, 3HAMP and specially TDoT are predicted to have a significantly lower $\alpha$-helical propensity and predicted $\beta$-strand segments are identified at their sequences (Additional file 1: Figures S4, S5).

The above-described analyses converge to indicate that the sequence of ZapB is more polar, less aggregation-prone, devoid of cryptic $\beta$-sheet regions, and with highest $\alpha$-helical and coiled-coil propensities than any previously used IBs tag. Each of these individual properties disfavors the potential aggregation of the ZapB sequence into $\beta$-sheet-rich aggregates. However, aggregation can still occur from the folded state of the proteins [67]. We have recently developed AGGRESCAN3D, an algorithm that allows predicting a protein's aggregationpropensity taking into account the structural context [68-70]. When we analyzed the published 3D structures of the three coiled-coil domains (ZapB, PDB:2JEE; TDoT, PDB:1FE6; and 3HAMP, PDB:3LNR), ZapB turned to be the less aggregation-prone structure, displaying a highly soluble surface (Additional file 1: Figure S6).

Finally, we assessed the net charge of the different IBs tagging sequences. This value is essential because if the high predicted solubility of ZapB comes together with a high positive charge, this will be a significant drawback for its use in nanomedical applications. Cationic sequences bind to negatively charged nucleic acids and cell membranes, which then become incorporated into IBs during their formation or purification, making them compositionally heterogeneous. The calculated net charge for the six tags is represented in 

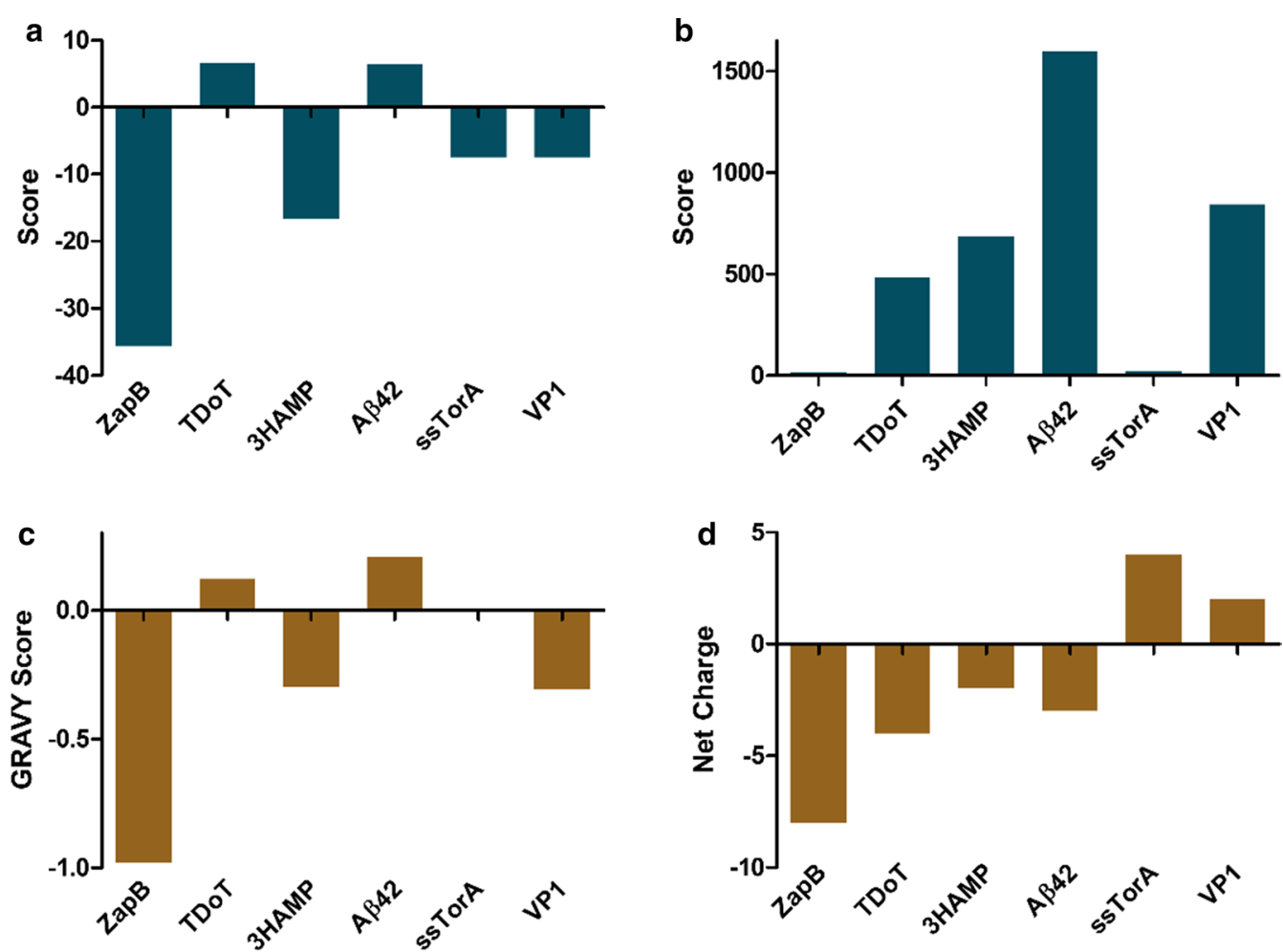

Fig. 2 Aggregation propensity predictions, hydrophaticity scores, and net charge values. Aggregation propensity values calculated with a Aggrescan (Na4vSS value) and b TANGO (AGG value) for the six selected tags. For both predictors, the more positive the value, the higher the aggregation propensity. c GRAVY hydrophaticity score of the different tags according to the Kyte-Doolittle scale. $\mathbf{d}$ The calculated net charge of the sequences at physiological pH

Fig. 2d. ZapB is the most acidic of the sequences (net charge -8$)$, the net charge being two times higher than that of the second most anionic tag (TDoT, net charge -4 ). These tags differ in their lengths. In order to obtain a value independent of the protein size, we calculated the net charge per residue (NCPR) (Additional file 1: Figure S7) [71]. According to the NCPR values, ZapB is again the most acidic tag (NCPR: -0.099 ), followed by TDoT (NCPR: -0.077 ). Therefore, no interaction is expected between DNA, RNA, or membranes and ZapB.

Overall, we can conclude that, theoretically, ZapB fulfills all the requirements to work as a tag to promote the formation of non-amyloid-like functional IBs; still, to act as such, the domain should be able to selfassemble, despite its high predicted solubility in both the folded and unfolded states.

\section{ZapB self-assembles into coiled-coil, non-amyloid, nanofibers}

In order to test the ability of ZapB to form protein assemblies driven by interactions between natively folded coiled-coils, a His-tag was added at the C-terminus of the full-length protein, and it was recombinantly produced in E.coli at $30^{\circ} \mathrm{C}$. The protein was expressed at high yield ( $>1 \mathrm{~g} / \mathrm{L}$ culture) (Additional file 1: Figure S8) and purified from the soluble cell fraction by IMAC. This soluble fraction was significantly viscous, and an imidazole gradient should be used for ZapB homogeneous purification (Additional file 1: Figure S9). This unusual viscosity already suggested a certain degree of ZapB self-assembly, which was further corroborated by transmission electron microscopy (TEM) analysis of the purified protein. Abundant long protein nanofibers $20 \pm 5 \mathrm{~nm}$ in width and displaying a regular striated pattern were observed (Fig. 3a), in excellent agreement with the nanostructures visualized in a previous study [42].

We analyzed the secondary structure content of self-assembled ZapB by circular dichroism (CD) spectroscopy. The spectrum is characteristic of an $\alpha$-helical structure, with two minima at $208 \mathrm{~nm}$ and $222 \mathrm{~nm}$ (Fig. 3b). Some studies have revealed that the $222 / 208 \mathrm{~nm}$ ratio allows discriminating individual $\alpha$-helices from coiled-coils, owing to the different periodicity of the two folds. A $222 / 208 \mathrm{~nm}$ ratio $\geq 1$ is 

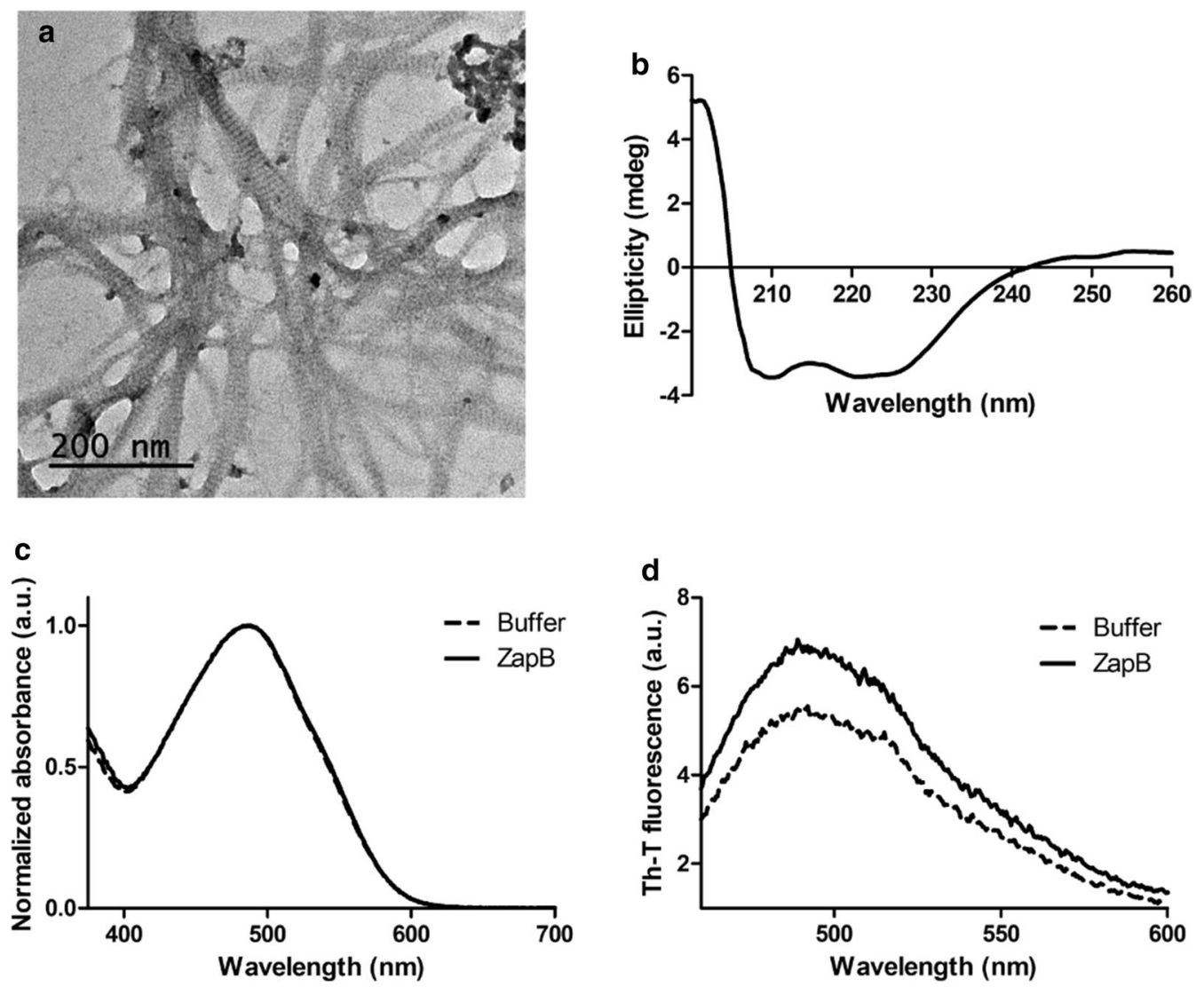

Fig. 3 ZapB coiled-coil assembly biophysical characterization. a TEM image of ZapB fibers upon negative staining. b Far-UV circular dichroism spectrum. c Congo-Red absorbance spectra and $\mathbf{d}$ Th-T fluorescence emission spectra

indicative of coiled-coil structures, and ratios $\leq 0.86$ can be attributed to individual $\alpha$-helices in a protein structure [72, 73]. For ZapB, the 222/208 nm ratio is 0.99 , indicating that, as anticipated by the protein crystal structure (PDB: 2JEE), ZapB keeps the coiledcoil fold in the macromolecular fibrillar assembly. The absence of a $\beta$-signature in the $C D$ spectrum of self-assembled ZapB is consistent with a non-amyloid nature. This trait was confirmed using the Congo Red (CR) and Thioflavin-T (Th-T) amyloid dyes. Both analyses indicated that the ZapB nanofibers do not have an amyloid-like nature, since the spectra of both dyes in the presence and absence of the protein (buffer alone) are fairly similar (Fig. 3c, d).

\section{ZapB IBs exhibit a coiled-coil conformation}

In order to explore whether, like the nanofilaments purified from the soluble cell fraction, ZapB IBs are sustained by coiled-coil interactions, they were purified from the insoluble cell fraction (Additional file 1: Figure S10) and their secondary structure content analyzed by $C D$ spectroscopy and Fourier Transform Infrared Spectroscopy (FTIR).

The Far-UV CD spectrum of ZapB IBs resembles the one obtained for the nanofibrillar solution (Fig. 4a). The packing of ZapB into IBs seems to favor the preservation of the coiled-coil conformation since the 222/208 nm ratio of these aggregates is 1.14. We recorded the infrared spectra of ZapB IBs in the amide I region of the spectrum (1700-1600 $\left.\mathrm{cm}^{-1}\right)$, corresponding to the absorption of the main chain carbonyl group and sensitive to protein conformation (Fig. 4b). It is important to note here, that in coiled-coils, the supercoil bending of the $\alpha$-helices results in a spectral splitting of the $\alpha$-helical IR amide I band and in a shift to lower wavenumbers [74]. FTIR measurements on the model coiled-coil GCN4 demonstrated the assignment of the solvated portion of the coiled-coil to a low helix frequency $\left(1631 \mathrm{~cm}^{-1}\right)$; in contrast, the buried helix frequency $\left(1651 \mathrm{~cm}^{-1}\right)$ is observed for residues in the interior of the coiled-coil. These two signals alone accounted for the $78 \%$ of the GCN4 spectral area $[75,76]$. Similarly, the major contributors to ZapB IBs IR spectra are two signals at $1632 \mathrm{~cm}^{-1}$ and 

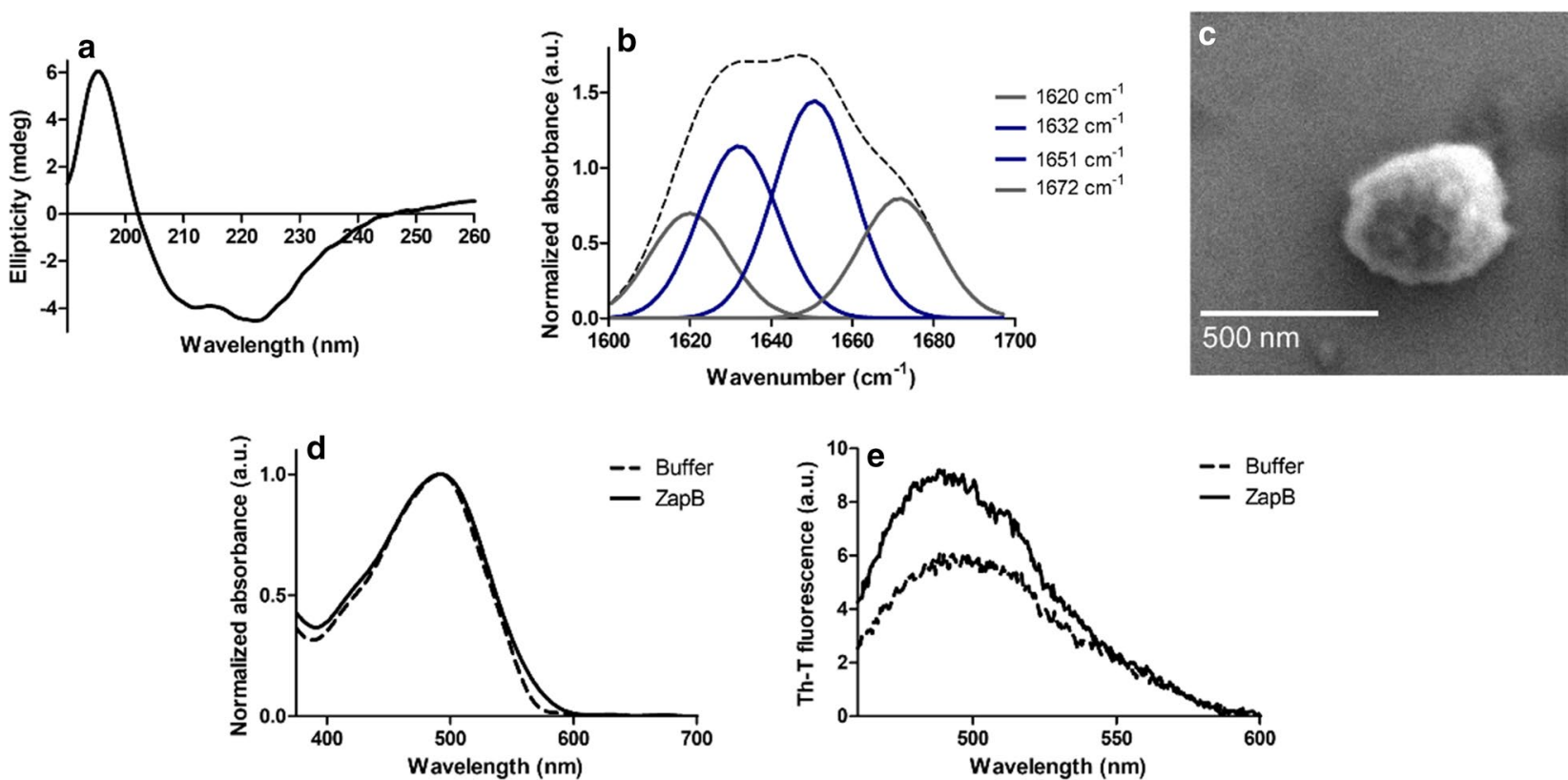

Fig. 4 Conformational properties of ZapB IBs. a Far-UV circular dichroism spectrum. b FTIR absorbance spectrum in the amide I region (dashed line). The different component bands (solid lines) were obtained by deconvolution of the absorbance spectrum. c SEM image of a ZapB IB. $\mathbf{d}$ Congo-Red absorbance spectra. eTh-T fluorescence emission spectra

$1651 \mathrm{~cm}^{-1}$ bands, accounting for the $28 \%$ and the $35 \%$ of the absorbance spectrum area, respectively. Additional bands at $1620 \mathrm{~cm}^{-1}$ and $1672 \mathrm{~cm}^{-1}$ were detected, the latest one being also present in the IR spectra of GCN4 and other coiled-coil proteins [75]. When observed using Scanning Electron Microscopy (SEM) (Fig. 4c), these IBs displayed a spherical shape. The non-amyloid nature of the IBs was confirmed using both CR and Th-T amyloid dyes, observing similar absorbance and fluorescence spectra for the IBs and the buffer alone, respectively (Fig. 4d, e).

Overall, the CD and FTIR data converge to indicate that ZapB IBs consist mostly of coiled-coil molecules.

\section{ZapB-GFP and ZapB-mCherry proteins are produced as fluorescent IBs in E. coli}

In order to test the ability of $\mathrm{ZapB}$ to assist the formation of functional IBs inside bacteria, ZapB was N-terminally fused to GFP and expressed in E. coli. After induction of protein expression, the soluble and the insoluble cellular fractions were separated by centrifugation and analyzed by SDS-PAGE. As shown in Fig. 5a, the ZapB-GFP fusion protein was mainly located in the insoluble fraction ( 95\%), whereas, non-tagged insoluble GFP accounts for $\sim 30 \%$ of the recombinant protein (Additional file 1: Figure S11). Thus, the fusion of the two polypeptides facilitates GFP deposition. We used fluorescence confocal microscopy to localize the GFP fluorescence emission in E. coli intact cells. As expected, the GFP signal was confined mainly in IBs placed at the poles of cells (Fig. 5b).

GFP is considered the default fluorescent protein for most applications, but when dealing with deep in vivo imaging, red-shifted fluorescent proteins are preferred since, at these wavelengths, light absorption by tissues is significantly lower [77], among them mCherry is one of the most used variants $[78,79]$. We N-terminally fused ZapB to mCherry, in order to asses if we can obtain red fluorescent IBs with potential in vivo applications.

ZapB-mCherry was expressed in E. coli, and the soluble and the insoluble fraction were separated as above. In this case, $\sim 55 \%$ of the fusion protein is present in the insoluble fraction (Fig. 6a), whereas in non-tagged mCherry only $\sim 5 \%$ of the protein is insoluble (Additional file 1: Figure S12). The difference between the fraction of ZapB-GFP and ZapB-mCherry located in the respective insoluble fractions likely owes to the highest solubility of the mCherry structure when compared with GFP, as assessed using the AGGRESCAN3D algorithm (Additional file 1: Figure S13). When the location of the red fluorescence was monitored using confocal microscopy, highly fluorescent IBs become evident at the poles. However, their discretization was more difficult than in the case of ZapB-GFP, due to the soluble fusion protein fluorescent background (Fig. 6b). 


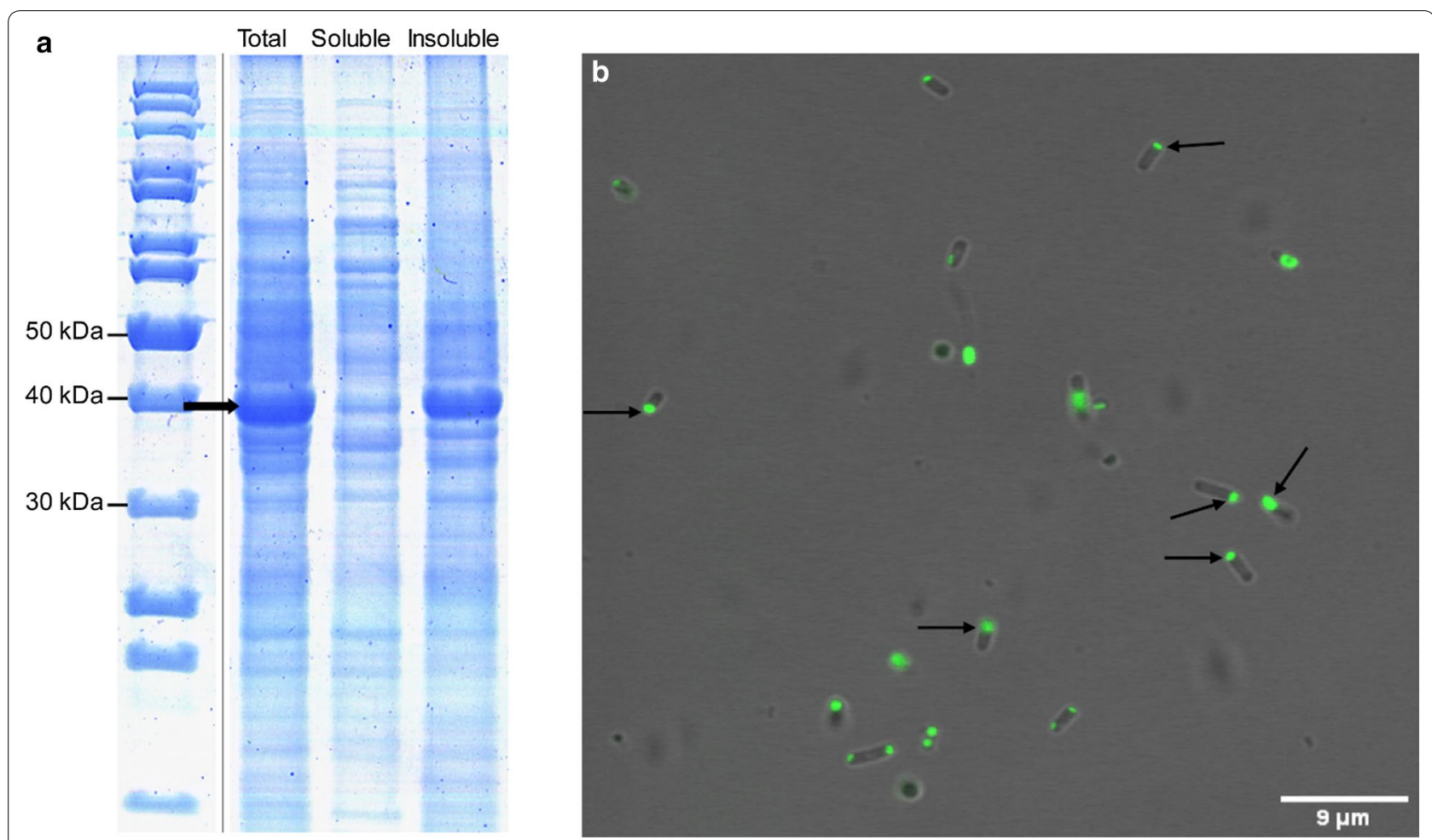

Fig. 5 Cellular distribution of ZapB-GFP IBs. a SDS-PAGE of intact cells, soluble, and insoluble cellular fractions. The arrow indicates the ZapB-GFP. b Visualization of ZapB-GFP IBs in intact E. coli cells by confocal microscopy. Some IBs located at the poles of cells are indicated

\section{GFP and mCherry maintain native spectral properties \\ in ZapB-based IBs}

In order to evaluate the impact of the coiled-coil structure in the functionality of the attached fluorescent proteins when embedded in the IBs, we purified both IBs from the insoluble fraction (Additional file 1: Figures S14, $\mathrm{S} 15)$. The analysis of the purified protein aggregates using an epifluorescence microscope and adequate filters allowed us to observe the presence of abundant green and red fluorescent particles for ZapB-GFP and ZapBmCherry, respectively (Fig. 7a,b). We compared the spectral properties of the fluorescent proteins trapped in the IBs with those of their soluble and non-tagged counterparts. As it is shown in Fig. 7c, soluble GFP and ZapB-GFP IBs presented identical excitation and emission maxima at 495-496 and $512 \mathrm{~nm}$, respectively. The same behavior was observed when comparing soluble mCherry with ZapB-mCherry IBs, both displaying excitation and emission maxima at 589 and $604 \mathrm{~nm}$, respectively (Fig. 7d). The emission spectra of ZapB-GFP and ZapB-mCherry overlap perfectly with that of the respective soluble untagged fluorescent proteins, whereas, in both cases, the left side of the excitation spectrum is slightly red-shifted when the protein is located within the IBs, which likely respond to differences in crowding and or mobility between soluble and assembled fluorescent proteins.

Overall, these results allow us to confirm that GFP and mCherry keep their activity and, likely, their native conformation inside ZapB-induced IBs.

\section{ZapB-GFP inclusion bodies contain a coiled-coil conformation}

We selected the ZapB-GFP fusion as a model system to further study the properties of ZapB promoted IBs. We analyzed the secondary structure content of these IBs using CD spectroscopy and FTIR. The far-UV CD spectrum of ZapB-GFP is of course influenced by the all $\beta$-sheet structure of GFP (Fig. 8a); still, the two main signatures of $\alpha$-helices could be detected in the IBs, with the global minimum placed at $222 \mathrm{~nm}$ and inflection of the spectrum at $208 \mathrm{~nm}$ (Fig. 8a).

When ZapB-GFP IBs were analyzed using FTIR in the amide I region of the spectrum, we could detect, again, the characteristic helical band at $1651 \mathrm{~cm}^{-1}$, accounting for $39 \%$ of the absorbance area. However, now the major signal is located at $1626 \mathrm{~cm}^{-1}$ (49\% of the area). This band, likely results from the sum of the low-frequency coiled-coil signal and the $\beta$-sheet signal of the fused GFP $\beta$-barrel (Fig. 8b). An additional band at $1678 \mathrm{~cm}^{-1}$, likely 


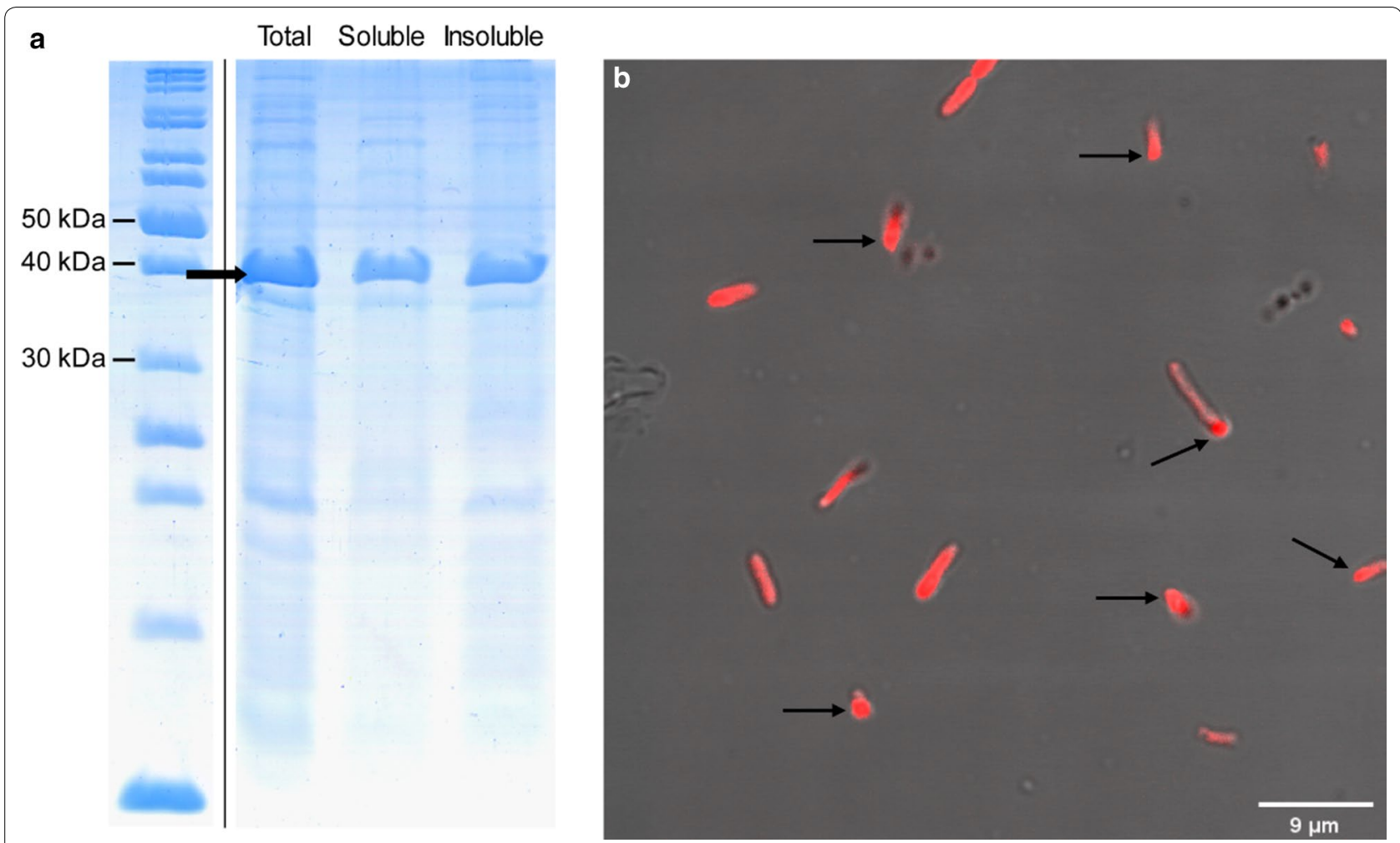

Fig. 6 Cellular distribution of ZapB-mCherry IBs. a SDS-PAGE of intact cells, soluble, and insoluble cellular fractions. The arrow indicates the ZapB-mCherry. b Visualization of ZapB-mCherry IBs in intact E. coli cells by confocal microscopy. Some IBs located at the poles of cells are indicated

arising from the mixed contribution of the two structurally different domains in the fusion at high frequencies was also evident. Finally, the non-amyloid character of ZapB-GFP IBs was corroborated using the CR amyloid dye, observing similar absorbance spectra in the presence of ZapB-GFP IBs, soluble GFP or only buffer (Fig. 8c).

Overall, the secondary structure analyses of ZapB-GFP IBs suggest that they contain a significant proportion of coiled-coil conformations and do not have an amyloidlike nature. This is likely also the case for ZapB-mCherry IBs, since their binding to $\mathrm{Th}-\mathrm{T}$ and $\mathrm{CR}$ are negligible (Additional file 1: Figure S16).

\section{Comparison of ZapB-based and amyloid-like IBs}

We wanted to compare the properties of the above described coiled-coil-based IBs with those of model amyloid-like IBs. To this aim, we selected fusion of the Alzheimer's related $\beta$-amyloid peptide (A $\beta 42)$ and GFP. In previous studies, we have characterized in detail the properties of A $342-$ GFP IBs $[22,80,81]$. The high amyloid propensity of the $A \beta 42$ peptide drives the incorporation of the GFP moiety into $\beta$-sheet enriched and fluorescent IBs.

We expressed A $\beta 42-$ GFP (Additional file 1: Figure S17) and purified its IBs (Additional file 1: Figure S18) and compared the spectral properties of GFP in these aggregates with those of ZapB-GFP. Figure 9a demonstrates that A 42 -GFP and ZapB-GFP IBs share the same excitation and emission spectra, indicating that the active and properly folded GFP they contain is in a similar environmental context. The size of the IBs was analyzed using dynamic light scattering (DLS). Both IBs exhibited similar sizes, with moderately polydisperse distributions and calculated average diameters of $462.2 \pm 69.51 \mathrm{~nm}$ and $463.3 \pm 99.9 \mathrm{~nm}$, for ZapB-GFP and A $342-$ GFP, respectively. The DLS data suggested that ZapB-GFP IBs are quite homogeneous in size (Additional file 1: Figure S19). Effectively, when these aggregates were imaged by Scanning Electron Microscopy (SEM), it was observed that they correspond to submicrometric spherical assemblies (Fig. 9b), and accordingly, they can be assimilated to protein nanoparticles.

Once confirmed that ZapB-GFP and A $442-$ GFP IBs share spectral properties and dimensions, we wondered if the GFP activity in both nanostructures was similar. To this aim, we analyzed the GFP fluorescence intensity of both IBs by fluorescence microscopy. The mean fluorescence intensity values as obtained from images (Additional file 1: Figure S20) quantification of 50 isolated fluorescent dots in each sample, using ImageJ, revealed 

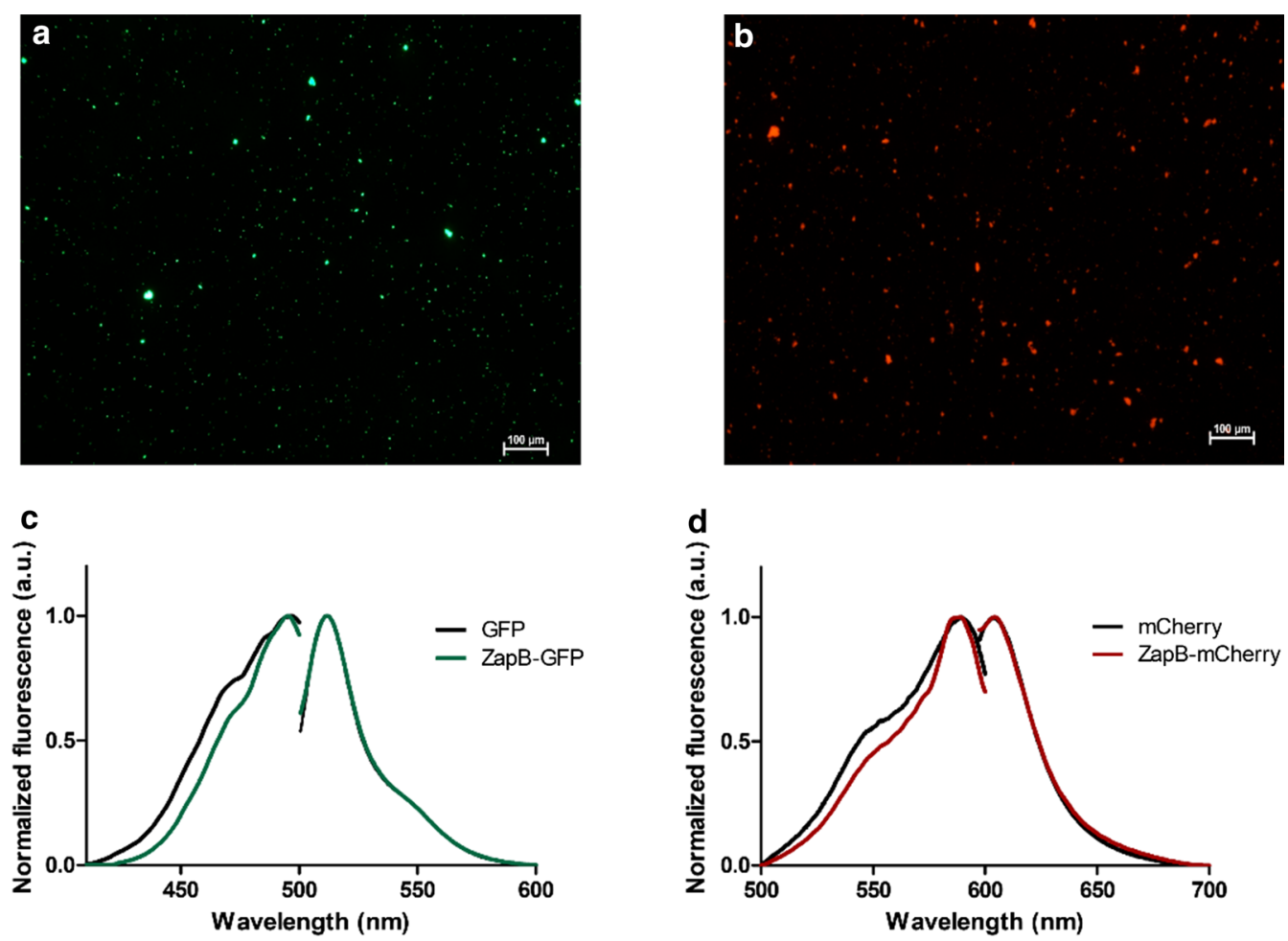

Fig. 7 Epifluorescence microscopy images and spectral properties of ZapB-GFP and ZapB-mCherry IBs. a Fluorescence microscopy image of purified ZapB-GFP IBs. b Fluorescence microscopy image of purified ZapB-mCherry IBs. c Excitation and emission spectra of ZapB-GFP IBs and soluble GFP. $\mathbf{d}$ Excitation and emission spectra of ZapB-mCherry IBs and soluble mCherry

that ZapB-GFP IBs exhibited two times higher activity (3713 \pm 91.25 a.u.) than A $342-G F P$ IBs $(1839 \pm 25.23$ a.u.) (Fig. 10). This observation is not surprising since the assembly of A $342-$-GFP IBs depends on an aberrant interaction between hydrophobic A $\beta 42$ regions, which leads to a relatively rapid aggregation into amyloid-like structures, with the subsequent inactivation of a least a fraction of the attached globular domains, with their most aggregation-prone sequence stretches contributing to stabilize the aggregate through amyloid-like contacts [22]. Indeed, we have demonstrated that the activities of the IBs formed by $20 \mathrm{~A} \beta 42-\mathrm{GFP}$ variants, bearing different mutations in the $A \beta 42$ moiety, inversely correlate with the aggregation propensities of the peptides [82]. A $342-G F P$ IBs inactivation was favored by increased $\beta$-sheet propensity and hydrophobicity and counteracted by increased net charge [54]. ZapB has a negligible $\beta$-sheet propensity, is polar, highly charged and has a very low aggregation propensity, compared with $\mathrm{A} \beta 42$, all these factors likely contributing to the higher activity of ZapB-GFP IBs. In addition, the inter- and supramolecular assembly of ZapB is directed by native interactions, and not by non-native contacts, as in $\mathrm{A} \beta 42$, which are expected to interfere less with the folding and structure of the GFP moiety, and indeed, many coiled-coil domains naturally exist and function appended to globular domains [83].

\section{ZapB-GFP IBs are innocuous for human cells}

One of the potential advantages of coiled-coil inspired IBs, relative to amyloid-like IBs, is that in the absence of intermolecular $\beta$-sheet assemblies that might elicit cytotoxicity, these $\alpha$-helical-based assemblies should be non-toxic for human cells. To confirm this extent, we incubated HeLa cells with increasing concentrations of ZapB-GFP IBs (from 0 to $12 \mu \mathrm{M}$ ) for $72 \mathrm{~h}$ and monitored their viability using PrestoBlue ${ }^{\circledR}$ fluorescent assay. As it can be observed in Fig. 11a, the IBs turned to be innocuous at any of the assayed concentrations, which should make them suitable for in vivo applications. This is contrast with A $342-G F P$ IBs, which exhibit a moderate and concentration-dependent toxicity for HeLa cells (Fig. 11b), in good agreement with the toxicity we described previously for A $\beta 42$ IBs [84]. 

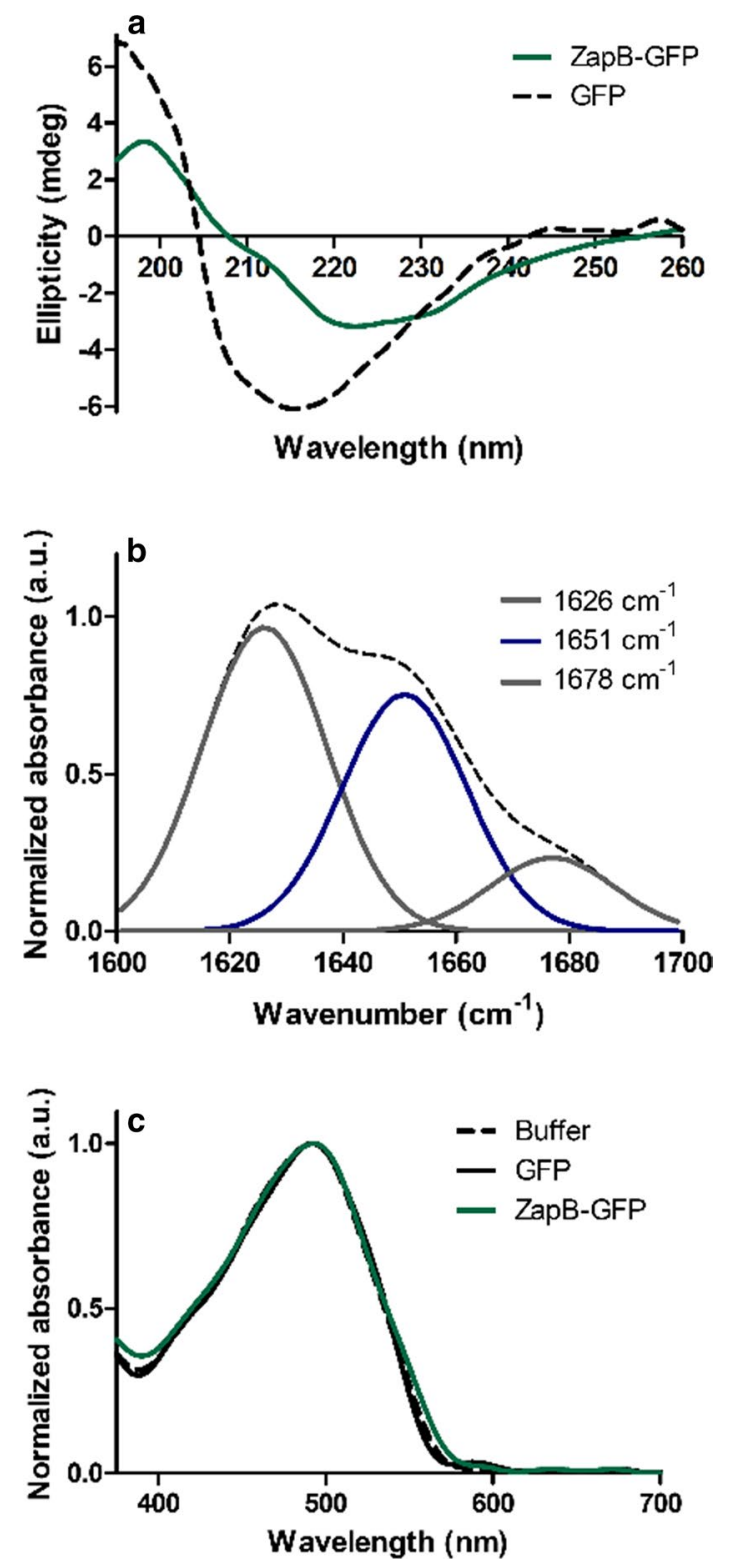

Fig. 8 Conformational properties of ZapB-GFP IBs. a Far-UV circular dichroism spectrum of ZapB-GFP IBs and soluble GFP. $\mathbf{b}$ FTIR absorbance spectrum of ZapB-GFP IBs in the amide I region (dashed line). The different component bands (solid lines) were obtained by deconvolution of the spectrum using PeakFit software. c Congo-Red absorbance spectra

\section{Conclusions}

IBs have been traditionally regarded as waste reservoirs containing only misfolded and thus non-active and useless proteins. However, it is now clear that at least some proteins can retain certain activity when embedded in these aggregates, turning them into functional sub-micron particles [23, 85]. These nanostructures are finding amazing applications in biotechnology [86] and biomedicine $[18,19]$.

Conventionally, IBs are enriched in intermolecular $\beta$-sheet structure, and contain both amyloid-like and native protein conformations [24]. Unavoidably, a fraction of the target protein becomes inactivated to form the amyloid skeleton that provides mechanical stability to IBs. In order to endorse IBs with tailored functionalities, the particular protein of interest is usually fused to an aggregation-prone polypeptide that act as IB-forming tag $[44,87]$. This allows to recruit otherwise soluble proteins into IBs. However, the high-aggregation potential of these tags compromises the folding of the target protein, a fraction of which establishes non-native contacts and becomes an integral part of the amyloid-like architecture, and thus inactive [22].

Because of their amyloidogenic nature, active IBs are assimilated to natural functional amyloids [88]. It is important to note here that, as pathogenic amyloids, functional amyloids found in nature are also inherently cytotoxic [29]; the difference being that nature has evolved dedicated mechanisms to prevent the toxicity of natural assemblies. In the absence of these control mechanisms it cannot can be completely discarded that amyloid-like IBs might contain or release toxic protein conformers.

A way to avoid protein inactivation by non-native interactions and potential toxicity is to run away from non-native- $\beta$-sheet based IBs and develop native- $\alpha$-helix based IBs. We take here a step towards this direction by implementing ZapB based IBs. Catalytic coiled-coil based IBs have been described previously [16, 17, 37-41]. However, our computational analysis suggests that these sequences display lower $\alpha$-helical and coiled-coil propensities and higher intrinsic aggregation propensities than ZapB, which suggests that a partial transition towards amyloid-like structures upon overexpression cannot be fully discarded, especially because the IBs they promoted were not conformationally characterized.

To avoid the above-mentioned $\alpha$-helix to $\beta$-sheet transition, we have selected ZapB. A natural sequence with extremely high $\alpha$-helical and coiled-coil propensities, a neglectable intrinsic aggregation propensity and a high polar and anionic character. This coiled-coil protein exhibits the ability to spontaneously assemble into $\alpha$-helical macromolecular fibrils devoid of any amyloid character. We show how this property can be exploited to obtain innocuous, spherical, relatively homogeneous and highly active sub-micrometric coiled-coil inspired IBs. ZapB expands our existing toolbox to generate immobilized enzymes or biomedical nanocarriers, among other applications. However, the present work constitutes a proof-of-concept, and the ability of ZapB to facilitate the 

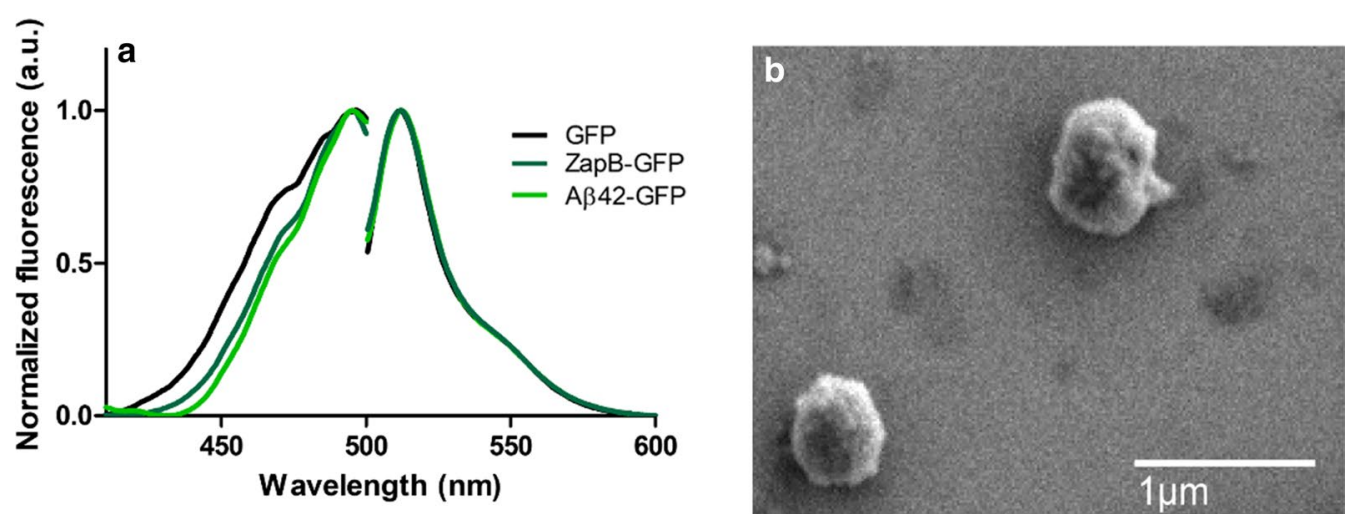

Fig. 9 Spectral properties and morphology of ZapB-GFP IBs. a GFP-Excitation and emission spectra of ZapB-GFP IBs, Aß42-GFP IBs, and soluble GFP. b SEM image of ZapB-GFP IBs

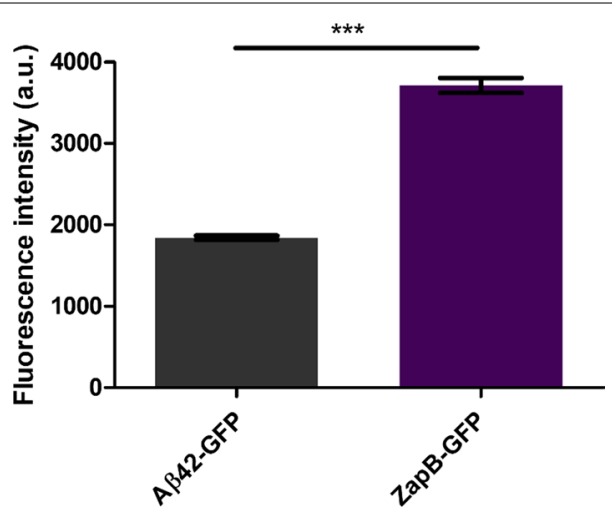

Fig. 10 GFP fluorescence of ZapB-GFP and Aß42-GFP inclusion bodies. Quantification of GFP fluorescence intensity from fluorescence microscopy images using ImageJ. The corresponding intensity of 50 individual fluorescent dots for each sample was analyzed and averaged. The statistical values were derived using the Mann-Whitney Test. A $p$ value $<0.001$ is indicated as ${ }^{* * *}$. Error bars correspond to SEM formation of functional IBs when fused to other protein folds should still be demonstrated.

\section{Methods}

\section{In silico analysis}

For the analysis of the coiled-coil tendency, four different predictors were used: Coils, DeepCoil, PCoils and MARCOIL. For the different predictions, the Coiled-coil probability (\%) was calculated in order to obtain a quantitative value of the coiled-coil tendency of the analyzed sequences.

Aggregation propensity predictions were performed using Aggrescan and TANGO webservers. In the case of Aggrescan, the Normalized a4v Sequence Sum for 100 residues $\left(\mathrm{Na}^{4} \mathrm{vSS}\right)$ was employed as the aggregation propensity value. In the case of TANGO, predictions were made using the default parameters and the $A G G$ value was selected as the aggregation propensity value.
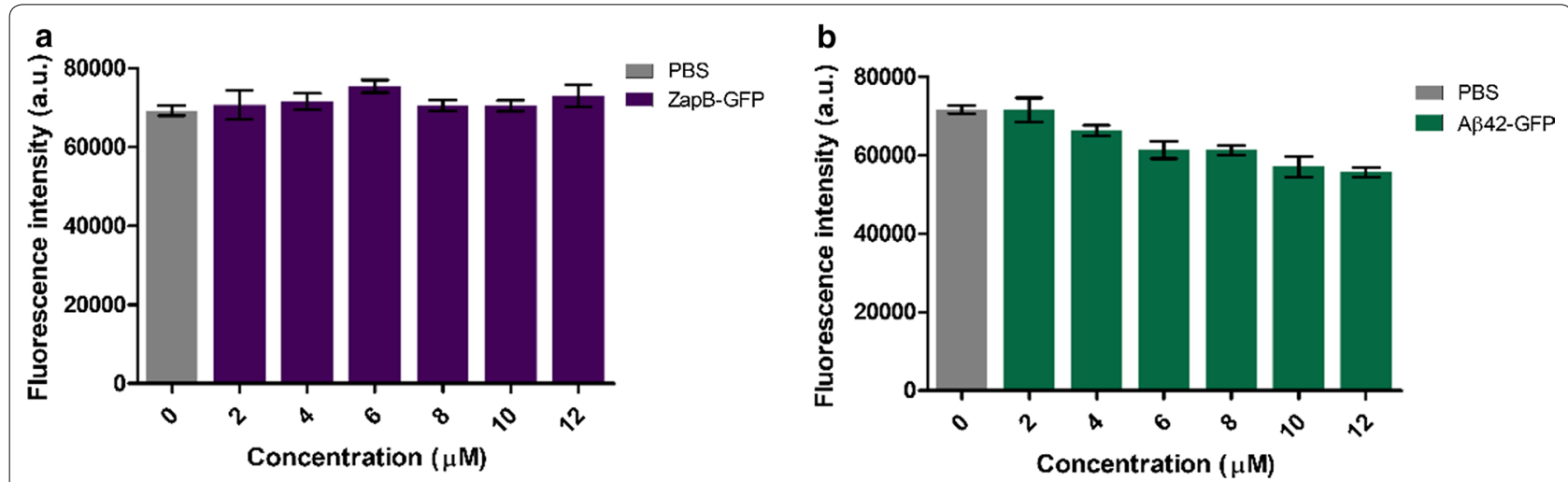

Fig. 11 Citotoxicity of ZapB-GFP and Aß42-GFP IBs. HeLa cells viability was assessed after adding different concentrations (from 2 to $12 \mu \mathrm{M}$ ) of ZapB-GFP a and Aß42-GFP b IBs for $72 \mathrm{~h}$. PBS buffer was used as a control 
For the aggregation propensity predictions considering the 3D structure, AGGRESCAN3D webserver was used with the default parameters and using the following PDBs as an input: PDB: 2JEE for ZapB, PDB: 1FE6 for TDoT and PDB: 3LNR for 3HAMP, PDB: 2Y0G for GFP and PDB: $2 \mathrm{H} 5 \mathrm{Q}$ for mCherry. In the case of ZapB and 3HAMP proteins, the dimeric structures were generated with PISA. Protein structures and their surfaces were represented with Pymol (DeLano Scientific, LLC).

The Grand Average of Hydropathicity (GRAVY score) and the net charge at physiological $\mathrm{pH}$ were calculated using the ProtParam tool. The net charge per residue (NCPR) was calculated dividing the net charge by the total number of residues.

Finally, secondary structure predictions were performed using GOR and PSIPRED webservers.

\section{Protein production and purification}

ZapB gene fragment (Additional file 1: DNA and amino acid sequences of ZapB protein) was cloned into a pET21a vector between NdeI and BamHI restriction sites. The ZapB-GFP and ZapB-mCherry fusion proteins were generated inserting both target proteins after ZapB sequence, using a linker (SIPGA) and BamHI and EcoRI restriction sites.

For the production of soluble and His-tagged ZapB, GFP and mCherry proteins, transformed E. coli BL21 (Invitrogen, USA) cells were grown aerobically in Luria Broth (LB) medium supplemented with $100 \mu \mathrm{g} / \mathrm{ml}$ of ampicillin. Protein expression was induced with $1 \mathrm{mM}$ Isopropyl $\beta$-D-1-thiogalactopyranoside (IPTG) at $30{ }^{\circ} \mathrm{C}$ for $12 \mathrm{~h}$. For protein purification, cells expressing the recombinant protein were harvested by centrifugation ( $5000 \mathrm{~g}$ for $20 \mathrm{~min}$ ). After cell lysis by sonication and fractionation, the soluble fraction was collected and injected in a Histrap FF $5 \mathrm{~mL}$ column (GE Healthcare, USA) using an ÄKTA (GE Healthcare, USA). After purification, proteins were dialyzed in buffer A $(50 \mathrm{mM}$ Tris, $100 \mathrm{mM}$ $\mathrm{NaCl}, \mathrm{pH}$ 7.4). The purity of these proteins was checked by SDS-PAGE.

For the production of ZapB, ZapB-GFP, ZapB-mCherry and A $342-G F P$ IBs, transformed E. coli BL21 (Invitrogen, USA) cells were grown aerobically in LB medium supplemented with $100 \mu \mathrm{g} / \mathrm{mL}$ of ampicillin for ZapB, ZapB-GFP and ZapB-mCherry transformed cells, and with $50 \mu \mathrm{g} / \mathrm{mL}$ of kanamycin for A $\beta 42-$ GFP transformed cells. Protein expression was induced with $1 \mathrm{mM}$ IPTG at $30{ }^{\circ} \mathrm{C}$ for $12 \mathrm{~h}$. For IBs purification, cells were centrifuged at $5000 \mathrm{~g}$ for $20 \mathrm{~min}$. After that, IBs were purified as described [89]. Briefly, pelleted cells were resuspended in $400 \mu \mathrm{L}$ of buffer A (50 mM Tris, $100 \mathrm{mM} \mathrm{NaCl}, \mathrm{pH}$ 7.4) plus $4 \mu \mathrm{L}$ of $100 \mathrm{mM}$ PMSF and $6 \mu \mathrm{L}$ of $10 \mathrm{mg} / \mathrm{mL}$ lysozyme. After $1 \mathrm{~h}$ of incubation at $37{ }^{\circ} \mathrm{C}$, the mixture was cooled in ice and sonicated $3 \mathrm{~min}$ at 15\% amplitude under $1 \mathrm{~s}$ cycles. After that, $4 \mu \mathrm{L}$ of Nonidet P40 (NP40) were added and the mixture incubated at $4{ }^{\circ} \mathrm{C}$ for $1 \mathrm{~h}$. Then, $10 \mu \mathrm{L}$ of $1 \mathrm{mg} / \mathrm{mL}$ DNase I and $12 \mu \mathrm{L}$ of $1 \mathrm{M}$ $\mathrm{MgSO}_{4}$ were added and the mixture was further incubated at $37^{\circ} \mathrm{C}$ for $45 \mathrm{~min}$. IBs were collected by centrifugation at $15.000 \mathrm{~g}$ for $15 \mathrm{~min}$ at $4{ }^{\circ} \mathrm{C}$ and washed with buffer A (50 mM Tris, $100 \mathrm{mM} \mathrm{NaCl}, \mathrm{pH} 7.4$ ) containing $0.5 \%$ Triton X-100. All incubations were done under gentle agitation. Finally, IBs were washed three times with buffer A ( $50 \mathrm{mM}$ Tris, $100 \mathrm{mM} \mathrm{NaCl}, \mathrm{pH}$ 7.4) to remove remaining detergent. The purity of the IBs was checked by SDS-PAGE. Protein concentration was estimated measuring the absorbance at $280 \mathrm{~nm}$ in a Specord 200 Plus spectrophotometer (Analytik Jena, Germany).

\section{Circular dichroism (CD) spectroscopy}

For the analysis of the secondary structure, ZapB protein, ZapB and ZapB-GFP IBs were exhaustively resuspended in buffer A (50 mM Tris, $100 \mathrm{mM} \mathrm{NaCl}, \mathrm{pH}$ 7.4). Soluble GFP was diluted in buffer A $(50 \mathrm{mM}$ Tris, $100 \mathrm{mM}$ $\mathrm{NaCl}, \mathrm{pH} 7.4)$ at $5 \mu \mathrm{M}$. Sedimentation problems were avoided with thorough resuspension of the sample before the measurements. The correct resuspension of the sample was checked before and after of each measurement. Far-UV CD spectra of the different protein solutions were recorded using a $1 \mathrm{~nm}$ bandwith, a response time of $1 \mathrm{~s}$, and a scan speed of $100 \mathrm{~nm} / \mathrm{min}$ in a Jasco-710 spectropolarimeter (Jasco Corporation, Japan), thermostated at $25{ }^{\circ} \mathrm{C}$. Ten accumulations were averaged for each spectrum.

\section{Transmission electron microscopy (TEM)}

For TEM sample preparation, $10 \mu \mathrm{L}$ of $10 \mu \mathrm{M}$ of ZapB protein were deposited onto a carbon-coated copper grid for $10 \mathrm{~min}$ and the excess of liquid was removed with filter paper, followed by a negative stain with $10 \mu \mathrm{L}$ of $2 \%$ (w/v) uranyl acetate for $1 \mathrm{~min}$. Grids were exhaustively scanned using a JEM 1400 transmission electron microscope (JEOL Ltd, Japan) operating at $80 \mathrm{kV}$, and images were acquired with a CCD GATAN ES1000W Erlangshen camera (Gatan Inc., USA). The width of fibers was analyzed using ImageJ, averaging the measures of 5 individual fibers.

\section{Scanning electron microscopy (SEM) and dynamic light scattering (DLS)}

Scanning electron microscopy (SEM) was used in order to analyze the morphology of ZapB and ZapB-GFP IBs. To do that, $10 \mu \mathrm{L}$ of sample resuspended in water were deposited on silicon wafers (Ted Pella Inc., USA), airdried and observed using a SEM Merlin (Zeiss Merlin, Germany) operating at $2 \mathrm{kV}$. 
Dynamic light scattering (DLS) was used for a quantitative determination of ZapB-GFP and A $\beta 42-$ GFP IBs size. The size of these nanoparticles was determined using a Zetasizer Nano ZS (Malvern Instruments Limited, UK) at $25{ }^{\circ} \mathrm{C}$. Three different measures of ten runs were recorded for each sample.

\section{Cell fractionation}

The distribution of the expressed ZapB, GFP, mCherry and the fusion proteins (ZapB-GFP, ZapB-mCherry and A $(42-G F P)$ in $E$. coli cells was analyzed by SDS-PAGE. After protein expression at $30^{\circ} \mathrm{C}$ for $12 \mathrm{~h}$, cells were harvested by centrifugation ( $5000 \mathrm{~g}$ for $20 \mathrm{~min}$ ) and resuspended in buffer A (50 mM Tris, $100 \mathrm{mM} \mathrm{NaCl}, \mathrm{pH}$ 7.4). After that, disrupted cells (total fraction) by sonication were centrifuged at $15.000 \mathrm{~g}$ for $15 \mathrm{~min}$ at $4{ }^{\circ} \mathrm{C}$, and supernatant (soluble fraction) was separated from pellet (insoluble fraction). The insoluble fraction was resuspended in the same volume of buffer A ( $50 \mathrm{mM}$ Tris, $100 \mathrm{mM} \mathrm{NaCl}$, $\mathrm{pH}$ 7.4) than the soluble fraction and the different fractions were heated at $98{ }^{\circ} \mathrm{C}$ for $10 \mathrm{~min}$. After that, $10 \mu \mathrm{L}$ of each fraction were loaded separately into SDS-PAGE. Band intensity quantification was performed using the ImageJ software in order to estimate the percentage of protein in each fraction.

\section{Confocal microscopy}

E. coli BL21 cells expressing ZapB-GFP and ZapBmCherry proteins at $30{ }^{\circ} \mathrm{C}$ for $12 \mathrm{~h}$ were centrifuged and resuspended in PBS pH 7.4 to an OD of 0.1. $10 \mu \mathrm{L}$ of resuspended cells were deposited on top of microscopy poly-L-lysine glass slides, covered with coverslips and observed in a Leica SP5 confocal fluorescence microscope (Leica Microsystems, Germany).

\section{Epifluorescence microscopy}

$10 \mu \mathrm{L}$ of the ZapB-GFP, ZapB-mCherry and A $\beta 42$-GFP IB samples in buffer A ( $50 \mathrm{mM}$ Tris, $100 \mathrm{mM} \mathrm{NaCl}, \mathrm{pH}$ 7.4) were deposited on top of microscopy glass slides and covered with coverslips. The fluorescence was observed using an Eclipse Ts2R-FL inverted microscope (Nikon, Japan) using a C-LED470 filter for GFP fluorescence and a C-LED525 for mCherry fluorescence.

To determine the GFP-fluorescence intensity of ZapBGFP and A 342 -GFP IBs, images were analyzed using the ImageJ software. 50 fluorescent dots were selected in each image maintaining the same dimensions (height $\times$ width) for the different selections. After that, the intensity of these different fluorescent dots was calculated and the average and SEM values were estimated.

\section{GFP and mCherry fluorescence spectra}

Excitation and emission spectra of soluble GFP, ZapBGFP IBs and A $\beta 42-$ GFP IBs in buffer A $(50 \mathrm{mM}$ Tris, $100 \mathrm{mM} \mathrm{NaCl}, \mathrm{pH}$ 7.4) were analyzed in a Jasco FP-8200 fluorescence spectrofluorometer (Jasco Corporation, Japan). Emission spectra were obtained recording the emitted fluorescence between 500 and $600 \mathrm{~nm}$. Excitation spectra were obtained by exciting the samples in a 400-500 nm range.

Excitation and emission spectra of soluble mCherry and ZapB-mCherry IBs in buffer A $(50 \mathrm{mM}$ Tris, $100 \mathrm{mM} \mathrm{NaCl}, \mathrm{pH}$ 7.4) were analyzed using Jasco FP-8200 fluorescence spectrofluorometer (Jasco Corporation, Japan). Emission spectra were obtained recording the emitted fluorescence between 600 and $700 \mathrm{~nm}$. Excitation spectra were obtained by exciting the samples in a 500-600 $\mathrm{nm}$. Three spectra were accumulated at $25^{\circ} \mathrm{C}$ with slit widths of $5 \mathrm{~nm}$, a $0.5 \mathrm{~nm}$ Interval, and a $1000 \mathrm{~nm} / \mathrm{min}$ scan rate for each sample.

\section{Fourier transform infrared spectroscopy (FTIR)}

Samples of ZapB and ZapB-GFP IBs were washed with $\mathrm{H}_{2} \mathrm{O}$ to remove the presence of salts. Both samples were placed on the ATR crystal and dried out under $\mathrm{N}_{2}$ flow. The experiments were carried out in a Bruker Tensor 27 FTIR (Bruker Optics, USA) supplied with a Specac Golden Gate MKII ATR accessory. Each spectrum consists of 32 acquisitions measured at a resolution of $1 \mathrm{~cm}^{-1}$. Data were acquired and normalized using the OPUS MIR Tensor 27 software (Bruker Optics, USA). IR spectrum was fitted employing a nonlinear peak-fitting equation using PeakFit package v4.12 (Systat Software, USA). The area for each Gaussian curve was calculated in the amide I region from 1700 to $1600 \mathrm{~cm}^{-1}$ using second derivative deconvolution method in PeakFit package v4.12 (Systat Software, USA).

\section{Toxicity assay}

HeLa cells were cultured in Dulbecco's Modified Eagle Medium (DMEM) supplemented with 10\% Fetal Bovine Serum (FBS) and seeded into 96-well plates. ZapB-GFP and A $\beta 42-G F P$ IBs were resuspended in PBS pH 7.4 and added at a range from 2 to $12 \mu \mathrm{M}$. For control, the same volume of PBS pH 7.4 was added. Treated and control cells were incubated for $72 \mathrm{~h}$ at $37^{\circ} \mathrm{C}$, and then $10 \mu \mathrm{L}$ of PrestoBlue ${ }^{\circledR}$ reagent (ThermoFisher Scientific, USA) was added and incubated for $10 \mathrm{~min}$. To determine cell viability, fluorescence signal was measured by exciting at $560 \mathrm{~nm}$ and collecting at $590 \mathrm{~nm}$ in a Victor3 fluorescent plate reader (Perkin Elmer, USA). 


\section{Thioflavin $\mathrm{T}$ (Th-T) and congo red (CR) binding}

For the Th-T binding assay, ZapB, mCherry. ZapB and ZapB-mCherry IBs, were diluted in buffer A $(50 \mathrm{mM}$ Tris, $100 \mathrm{mM} \mathrm{NaCl}, \mathrm{pH}$ 7.4) and incubated with $25 \mu \mathrm{M}$ Th-T. Emission fluorescence was recorded using a Jasco FP-8200 spectrofluorometer (Jasco Corporation, Japan) in the 460-600 $\mathrm{nm}$ range, using an excitation wavelength of $440 \mathrm{~nm}$ and an emission bandwith of $5 \mathrm{~nm}$. The same buffer with $25 \mu \mathrm{M}$ Th-T and without protein was employed as a control. In the case of ZapB-GFP, Th-T binding assay was not performed due to an overlap between the fluorescence spectra of GFP and Th-T.

For the CR binding assay the different IBs and soluble proteins were diluted in buffer A (50 mM Tris, $100 \mathrm{mM}$ $\mathrm{NaCl}, \mathrm{pH} 7.4$ ) and mixed with $\mathrm{CR}$ to a final concentration of $10 \mu \mathrm{M}$ CR. Optical absorption spectrum was recorded in the range from 375 to $700 \mathrm{~nm}$ in a Specord 200 Plus spectrophotometer (Analytik Jena, Germany). Spectrum of protein alone was acquired to subtract protein scattering.

\section{Supplementary information}

Supplementary information accompanies this paper at https://doi. org/10.1186/s12934-020-01375-4.

Additional file 1: Figure S1. Coiled-coil predictions for ZapB. Figure S2. Coiled-coil predictions for 3HAMP. Figure S3. Coiled-coil predictions for TDoT. Figure S4. Secondary structure prediction by PSIPRED server. Figure S5. Secondary structure prediction by GOR server. Figure S6. AGGRESCAN3D structural aggregation propensity predictions for ZapB, TDOT and 3HAMP. Figure S7. Net charge per residue (NCPR) of the different tags. Figure S8. SDS-PAGE of the cellular distribution of ZapB. Figure S9. SDS-PAGE of ZapB purification by IMAC. Figure S10. SDS-PAGE of purified ZapB IBs. Figure S11. SDS-PAGE of the cellular distribution of GFP. Figure S12. SDS-PAGE of the cellular distribution of mCherry. Figure S13. AGGRESCAN3D structural aggregation propensity predictions for GFP and mCherry. Figure S14. SDS-PAGE of purified ZapB-GFP IBs. Figure S15. SDS-PAGE of purified ZapB-mCherry IBs. Figure S16. Characterization of the non-amyloid nature of ZapB-mCherry IBs. Figure S17. SDS-PAGE of the cellular distribution of Aß42-GFP. Figure S18. SDS-PAGE of purified A $342-G F P$ IBs. Figure S19. DLS spectra of ZapB-GFP and Aß42-GFP IBs. Figure S20. Epifluorescence microscopy images of ZapB-GFP and A 342 GFP IBs. DNA and amino acid sequences of ZapB protein.

\section{Acknowledgements}

We are grateful to UAB microscopy service of Barcelona for their technical advice.

\section{Authors' contributions}

MGG contributed to acquisition, and analysis of data, preparation of the manuscript and carried out the experiments and analysis. SN carried out the cytotoxicity experiments. SV contributed to the concept and design of the investigation in addition to data analysis, preparation and revision of the manuscript. All authors read and approved the final manuscript.

\section{Funding}

This work was funded by the Spanish Ministry of Economy and Competitiveness BIO2016-78310-R to S.V and by ICREA, ICREA-Academia 2015 to S.V. M.G.G. was supported by the Spanish Ministry of Science and Innovation via a doctoral grant (FPU16/02465).

\section{Availability of data and materials}

All data generated and analyzed during this study are shown in this article and it Additional file 1.

\section{Ethics approval and consent to participate}

Not applicable.

\section{Consent for publication}

We state that all the authors (Marcos Gil-Garcia, Susanna Navarro and Salvador Ventura) mutually agree that this research work should be submitted to Microbial Cell Factories; it is an original work of the above-mentioned authors; and that the article has not been published or submitted in any other peerreviewed journal.

\section{Competing interests}

The authors declare that they have no competing interests.

Received: 26 March 2020 Accepted: 25 May 2020

Published online: 01 June 2020

\section{References}

1. Ferrer-Miralles N, Domingo-Espín J, Corchero J, Vázquez E, Villaverde A. Microbial factories for recombinant pharmaceuticals. Microb Cell Fact. 2009;8:1-8.

2. Rosano GL, Ceccarelli EA. Recombinant protein expression in Escherichia coli: advances and challenges. Front Microbiol. 2014;5:1-17.

3. Schrödel A, De Marco A. Characterization of the aggregates formed during recombinant protein expression in bacteria. BMC Biochem. 2005:6:1-11.

4. De Marco A. Recombinant polypeptide production in E. coli: towards a rational approach to improve the yields of functional proteins. Microb Cell Fact. 2013;12:1-8.

5. Tartaglia GG, Pechmann S, Dobson CM, Vendruscolo M. Life ond the edge: a link between gene expression levels and aggregation rates of human proteins. Trends Biochem Sci. 2007;32:204-6.

6. Villaverde A, Carrio MM. Protein aggregation in recombinant bacteria: biological role of inclusion bodies. Biotechnol Lett. 2003;25:1385-95.

7. Slouka C, Kopp J, Spadiut O, Herwig C. Perspectives of inclusion bodies for bio-based products: curse or blessing? Appl microbiol biotechnol. Appl Microbiol Biotechnol. 2019;103:1143-53.

8. Rinas U, Garcia-Fruitós E, Corchero JL, Vázquez E, Seras-Franzoso J, Villaverde A. Bacterial inclusion bodies: discovering their better half. Trends Biochem Sci. 2017;42:726-37.

9. García-Fruitós E, Rodríguez-Carmona E, Díez-Gil C, Ferraz RM, Vázquez E Corchero $J$, et al. Surface cell growth engineering assisted by a novel bacterial nanomaterial. Adv Mater. 2009;21:4249-53.

10. García-Fruitós E, Seras-Franzoso J, Vazquez E, Villaverde A. Tunable geometry of bacterial inclusion bodies as substrate materials for tissue engineering. Nanotechnology. 2010;21:205101.

11. De Marco A, Ferrer-Miralles N, Garcia-Fruitós E, Mitraki A, Peternel S, Rinas $U$, et al. Bacterial inclusion bodies are industrially exploitable amyloids. FEMS Microbiol Rev. 2019;43:53-72.

12. Margreiter G, Messner P, Caldwell KD, Bayer K. Size characterization of inclusion bodies by sedimentation field- flow fractionation. J Biotechnol. 2015;138:67-73.

13. Rinas U, Bailey JE. Protein compositional analysis of inclusion bodies produced in recombinant Escherichia coli. Appl Microbiol Biotechnol. 1992;37:609-14.

14. Carrió MM, Villaverde A. Construction and deconstruction of bacterial inclusion bodies. J Biotechnol. 2002;96:3-12.

15. Fahnert B, Lilie $H$, Neubauer P. Inclusion bodies: formation and utilisation. Adv Biochem Eng Biotechnol. 2004;89:93-142.

16. Jäger VD, Lamm R, Kloß R, Kaganovitch E, Grünberger A, Pohl M, et al. A synthetic reaction cascade implemented by colocalization of two proteins within catalytically active inclusion bodies. ACS Synth Biol. 2018;7:2282-95.

17. Krauss U, Jäger VD, Diener M, Pohl M, Jaeger KE. Catalytically-active inclusion bodies - carrier-free protein immobilizates for application in biotechnology and biomedicine. J Biotechnol. 2017;258:136-47. 
18. Pesarrodona M, Jauset T, Díaz-Riascos ZV, Sánchez-Chardi A, Beaulieu $M E$, Seras-Franzoso J, et al. Targeting antitumoral proteins to breast cancer by local administration of functional inclusion bodies. Adv Sci. 2019;6:1900849.

19. Céspedes MV, Cano-Garrido O, Álamo P, Sala R, Gallardo A, Serna N, et al. Engineering secretory amyloids for remote and highly selective destruction of metastatic foci. Adv Mater. 2019;1907348:1-9.

20. Ventura S, Villaverde A. Protein quality in bacterial inclusion bodies. Trends Biotechnol. 2006;24:179-85.

21. Carrió M, González-Montalbán N, Vera A, Villaverde A, Ventura S. Amyloid-like properties of bacterial inclusion bodies. J Mol Biol. 2005;347:1025-37.

22. Morell M, Bravo R, Espargaró A, Sisquella X, Avilés FX, FernàndezBusquets $X$, et al. Inclusion bodies: specificity in their aggregation process and amyloid-like structure. Biochim Biophys Acta Mol Cell Res. 2008;1783:1815-25.

23. García-Fruitós E, González-Montalbán N, Morell M, Vera A, Ferraz RM, Arís A, et al. Aggregation as bacterial inclusion bodies does not imply inactivation of enzymes and fluorescent proteins. Microb Cell Fact BioMed Central. 2005;4:1-6.

24. García-Fruitós E, Sabate R, De Groot NS, Villaverde A, Ventura S. Biological role of bacterial inclusion bodies: a model for amyloid aggregation. FEBS J. 2011;278:2419-27.

25. Cano-Garrido O, Rodríguez-Carmona E, Díez-Gil C, Vázquez E, Elizondo E, Cubarsi R, et al. Supramolecular organization of protein-releasing functional amyloids solved in bacterial inclusion bodies. Acta Biomater 2013:9:6134-42.

26. Fowler DM, Koulov AV, Balch WE, Kelly JW. Functional amyloid—from bacteria to humans. Trends Biochem Sci. 2007;32:217-24.

27. Fowler DM, Koulov AV, Alory-Jost C, Marks MS, Balch WE, Kelly JW. Functional amyloid formation within mammalian tissue. PLoS Biol. 2006;4:0100-7.

28. Maji SK, Perrin MH, Sawaya MR, Jessberger S, Vadodaria K, Rissman RA, et al. Functional amyloids as natural storage of peptide hormones in pituitary secretory granules. Science. 2009;325:328-32.

29. Jackson MP, Hewitt EW. Why are functional amyloids non-toxic in humans? Biomolecules. 2017;7:1-13.

30. Berson JF, Theos AC, Harper DC, Tenza D, Raposo G, Marks MS. Proprotein convertase cleavage liberates a fibrillogenic fragment of a resident glycoprotein to initiate melanosome biogenesis. J Cell Biol. 2003;161:521-33.

31. Guyonnet B, Egge N, Cornwall GA. Functional amyloids in the mouse sperm acrosome. Mol Cell Biol. 2014;34:2624-34.

32. Huang PS, Oberdorfer G, Xu C, Pei XY, Nannenga BL, Rogers JM, et al. High thermodynamic stability of parametrically designed helical bundles. Science. 2014;346:481-5.

33. Fletcher JM, Harniman RL, Barnes FRH, Boyle AL, Collins A, Mantell J, et al. Self-assembling cages from coiled-coil peptide modules. Science. 2013;340:595-9.

34. Ing NL, Spencer RK, Luong SH, Nguyen HD, Hochbaum Al. Electronic conductivity in biomimetic a-helical peptide nanofibers and gels. ACS Nano. 2018;12:2652-61.

35. Gradišar H, Božič S, Doles T, Vengust D, Hafner-Bratkovič I, Mertelj A, et al. Design of a single-chain polypeptide tetrahedron assembled from coiled-coil segments. Nat Chem Biol. 2013;9:362-6.

36. Ljubetič A, Lapenta F, Gradišar H, Drobnak I, Aupič J, Strmšek Ž, et al. Design of coiled-coil protein-origami cages that self-assemble in vitro and in vivo. Nat Biotechnol. 2017;35:1094-101.

37. Jäger VD, Kloss R, Grünberger A, Seide S, Hahn D, Karmainski T, et al. Tailoring the properties of (catalytically)-active inclusion bodies. Microb Cell Fact. BioMed Central. 2019;18:1-20.

38. Diener M, Kopka B, Pohl M, Jaeger KE, Krauss U. Fusion of a coiled-coil domain facilitates the high-level production of catalytically active enzyme inclusion bodies. ChemCatChem. 2016;8:142-52.

39. Lamm R, Jäger VD, Heyman B, Berg C, Cürten C, Krauss U, et al. Detailed small-scale characterization and scale-up of active YFP inclusion body production with Escherichia coli induced by a tetrameric coiled coil domain. Elsevier Ltd: J Biosci Bioeng; 2020.

40. Kloss R, Limberg MH, Mackfeld U, Hahn D, Grünberger A, Jäger VD, et al. Catalytically active inclusion bodies of $\mathrm{L}$-lysine decarboxylase from $\mathrm{E}$. coll for 1,5-diaminopentane production. Sci Rep. 2018;8:1-11.
41. Kloss R, Karmainski T, Jäger VD, Hahn D, Grünberger A, Baumgart M, et al. Tailor-made catalytically active inclusion bodies for different applications in biocatalysis. Catal Sci Technol. 2018;8:5816-26.

42. Ebersbach G, Galli E, Møller-Jensen J, Löwe J, Gerdes K. Novel coiled-coil cell division factor ZapB stimulates $Z$ ring assembly and cell division. Mol Microbiol. 2008;68:720-35.

43. Den Blaauwen T. Prokaryotic cell division: flexible and diverse. Curr Opin Microbiol. 2013;16:738-44.

44. Wang X, Zhou B, Hu W, Zhao Q, Lin Z. Formation of active inclusion bodies induced by hydrophobic self-assembling peptide GFIL8. Microb Cell Fact. 2015;14:1-8.

45. Rueda F, Gasser B, Sánchez-Chardi A, Roldán M, Villegas S, Puxbaum V, et al. Functional inclusion bodies produced in the yeast Pichia pastoris. Microb Cell Fact. 2016;15:166.

46. Pelassa I, Corà D, Cesano F, Monje FJ, Montarolo PG, Fiumara F. Association of polyalanine and polyglutamine coiled coils mediates expansion disease-related protein aggregation and dysfunction. Hum Mol Genet. 2014; 23:3402-20

47. Päiviö A, Nordling E, Kallberg Y, Thyberg J, Johansson J. Stabilization of discordant helices in amyloid fibril-forming proteins. Protein Sci. 2004;13:1251-9.

48. Brandenburg E, Von Berlepsch H, Gerling UIM, Böttcher C, Koksch B. Inhibition of amyloid aggregation by formation of helical assemblies. Chem A Eur J. 2011;17:10651-61.

49. Lupas A, Van Dyke M, Stock J. Predicting coiled coils from protein sequences. Science. 1991;252:1162-4.

50. Gruber M, Söding J, Lupas AN. Comparative analysis of coiled-coil prediction methods. J Struct Biol. 2006;155:140-5.

51. Delorenzi M, Speed T. An HMM model for coiled-coil domains and a comparison with PSSM-based predictions. Bioinformatics. 2002;18:617-25.

52. Ludwiczak J, Winski A, Szczepaniak K, Alva V, Dunin-Horkawicz S. DeepCoil-a fast and accurate prediction of coiled-coil domains in protein sequences. Bioinformatics. 2019;35:2790-5.

53. Villar-Piqué A, Espargaró A, Sabaté R, de Groot NS, Ventura S. Using bacterial inclusion bodies to screen for amyloid aggregation inhibitors. Microb Cell Fact. 2012;11:1-11.

54. De Groot NS, Aviles FX, Vendrell J, Ventura S. Mutagenesis of the central hydrophobic cluster in Aß42 Alzheimer's peptide: side-chain properties correlate with aggregation propensities. FEBS J. 2006;273:658-68.

55. García-Fruitós E, Arís A, Villaverde A. Localization of functional polypeptides in bacterial inclusion bodies. Appl Environ Microbiol. 2007;73:289-94.

56. Jong WSP, Vikström D, Houben D, Berg van Saparoea HB, Gier JW, Luirink J. Application of an E. coli signal sequence as a versatile inclusion body tag. Microb Cell Fact. 2017;16:1-13.

57. Jong WSP, ten Hagen-Jongman CM, Vikström D, Dontje W, Abdallah AM, de Gier JW, et al. Mutagenesis-based characterization and improvement of a novel inclusion body tag. Front Bioeng Biotechnol. 2020;7:1-13.

58. Conchillo-Solé O, de Groot NS, Avilés FX, Vendrell J, Daura X, Ventura S. AGGRESCAN: a server for the prediction and evaluation of "hot spots" of aggregation in polypeptides. BMC Bioinform. 2007:8:65.

59. Fernandez-Escamilla AM, Rousseau F, Schymkowitz J, Serrano L. Prediction of sequence-dependent and mutational effects on the aggregation of peptides and proteins. Nat Biotechnol. 2004;22:1302-6.

60. Chiti F, Calamai M, Taddei N, Stefani M, Ramponi G, Dobson CM. Studies of the aggregation of mutant proteins in vitro provide insights into the genetics of amyloid diseases. Proc Natl Acad Sci USA. 2002;99:16419-26.

61. Chiti F, Stefani M, Taddei N, Ramponi G, Dobson CM. Rationalization of the effects of mutations on peptide and protein aggregation rates. Nature. 2003:424:805-8.

62. Kyte J, Doolittle RF. A simple method for displaying the hydropathic character of a protein. J Mol Biol. 1982;157:105-32.

63. Kallberg Y, Gustafsson M, Persson B, Thyberg J, Johansson J. Prediction of amyloid fibril-forming proteins. J Biol Chem. 2001;276:12945-50.

64. Gendoo DM, Harrison PM. Discordant and chameleon sequences: their distribution and implications for amyloidogenicity. Protein Sci. 2011;20:567-79.

65. McGuffin $L$, Bryson $K$, Jones DT. The PSIPRED protein structure prediction server. Bioinformatics. 2000;16:404-5. 
66. Garnier J, Osguthorpe DJ, Robson B. Analysis of the accuracy and implications of simple methods for predicting the secondary structure of globular proteins. J Mol Biol. 1978;120:97-120.

67. Gil-Garcia M, Banó-Polo M, Varejao N, Jamroz M, Kuriata A, Díaz-Caballero $M$, et al. Combining structural aggregation propensity and stability predictions to redesign protein solubility. Mol Pharm. 2018;15:3846-59.

68. Zambrano R, Jamroz M, Szczasiuk A, Pujols J, Kmiecik S, Ventura S. AGGRESCAN3D (A3D): server for prediction of aggregation properties of protein structures. Nucleic Acids Res. 2015;43:W306-13.

69. Kuriata A, Iglesias V, Kurcinski M, Ventura S, Kmiecik S. Aggrescan3D standalone package for structure-based prediction of protein aggregation properties. Bioinformatics. 2019;35:3834-5.

70. Kuriata A, Iglesias V, Pujols J, Kurcinski M, Kmiecik S, Ventura S. Aggrescan3D (A3D) 2.0: prediction and engineering of protein solubility. Nucleic Acids Res. 2019;47:W300-7.

71. Tedeschi G, Mangiagalli M, Chmielewska S, Lotti M, Natalello A, Brocca $\mathrm{S}$. Aggregation properties of a disordered protein are tunable by $\mathrm{pH}$ and depend on its net charge per residue. Biochim Biophys Acta. 2017;1861:2543-50.

72. Zhou NE, Zhu B-Y, Kay CM, Hodges RS. The two-stranded a-helical coiledcoil is an ideal model for studying protein stability and subunit interactions. Biopolymers. 1992;32:419-26.

73. Zhou NE, Kay CM, Hodges RS. Synthetic model proteins: the relative contribution of leucine residues at the nonequivalent positions of the 3-4 hydrophobic repeat to the stability of the two-stranded a-helical coiled-coil. Biochemistry. 1992;31:5739-46.

74. Reisdorf WC, Krimm S. Infrared amide l' band of the coiled coil. Biochemistry. 1996:35:1383-6.

75. Heimburg T, Schünemann J, Weber K, Geisler N. FTIR-spectroscopy of multistranded coiled coil proteins. Biochemistry. 1999;38:12727-34.

76. Manas ES, Getahun Z, Wright WW, DeGrado WF, Vanderkooi JM. Infrared spectra of amide groups in a-helical proteins: evidence for hydrogen bonding between helices and water. J Am Chem Soc. 2000;122:9883-90.

77. Deliolanis NC, Kasmieh R, Wurdinger T, Tannous BA, Shah K, Ntziachristos $\checkmark$. Performance of the red-shifted fluorescent proteins in deep-tissue molecular imaging applications. J Biomed Opt. 2008;13:044008.

78. Shaner NC, Steinbach PA, Tsien RY. A guide to choosing fluorescent proteins. Nat Methods. 2005;2:905-9.
79. Shaner NC, Patterson GH, Davidson MW. Advances in fluorescent protein technology. J Cell Sci. 2007;120:4247-60.

80. De Groot NS, Ventura S. Effect of temperature on protein quality in bacterial inclusion bodies. FEBS Lett. 2006;580:6471-6.

81. De Groot NS, Sabate R, Ventura S. Amyloids in bacterial inclusion bodies. Trends Biochem Sci. 2009;34:408-16.

82. de Groot NS, Ventura S. Protein activity in bacterial inclusion bodies correlates with predicted aggregation rates. J Biotechnol. 2006;125:110-3.

83. Lupas AN, Gruber M. The structure of a-helical coiled coils. Adv Prot Chem. 2005;70:37-78.

84. Dasari M, Espargaro A, Sabate R, Lopez Del Amo JM, Fink U, Grelle G, et al. Bacterial inclusion bodies of alzheimer's disease $\beta$-amyloid peptides can be employed to study native-like aggregation intermediate states. ChemBioChem. 2011;12:407-23.

85. Gifre-Renom L, Seras-Franzoso J, Rafael D, Andrade F, Cano-Garrido O, Martinez-Trucharte F, et al. The biological potential hidden in inclusion bodies. Pharmaceutics. 2020;12:157.

86. Wang R, Li J, Dang D, Hu J, Hu Y, Fan J. Bacterial production of maize and human serine racemases as partially active inclusion bodies for D-serine synthesis. Enzyme Microb Technol. 2020;137:109547.

87. Carratalá JV, Cano-Garrido O, Sánchez J, Membrado C, Pérez E, ConchilloSolé $\mathrm{O}$, et al. Aggregation-prone peptides modulate activity of bovine interferon gamma released from naturally occurring protein nanoparticles. N Biotechnol. 2020;57:11-9.

88. Céspedes MV, Fernández Y, Unzueta U, Mendoza R, Seras-Franzoso J, Sánchez-Chardi A, et al. Bacterial mimetics of endocrine secretory granules as immobilized in vivo depots for functional protein drugs. Sci Rep. 2016;6:1-10.

89. Rodríguez-Carmona E, Cano-Garrido O, Seras-Franzoso J, Villaverde A García-Fruitós E. Isolation of cell-free bacterial inclusion bodies. Microb Cell Fact. 2010;9:1-9.

\section{Publisher's Note}

Springer Nature remains neutral with regard to jurisdictional claims in published maps and institutional affiliations.
Ready to submit your research? Choose BMC and benefit from:

- fast, convenient online submission

- thorough peer review by experienced researchers in your field

- rapid publication on acceptance

- support for research data, including large and complex data types

- gold Open Access which fosters wider collaboration and increased citations

- maximum visibility for your research: over 100M website views per year

At BMC, research is always in progress.

Learn more biomedcentral.com/submissions 